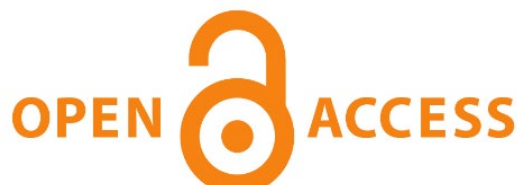

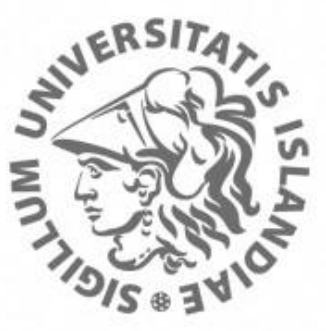

O. Opin vísindi

This is not the published version of the article / Petta er ekki útgefna útgáfa greinarinnar

Author(s)/Höf.: Hvannberg, Ebba Póra

Title/Titill: Identifying and explicating knowledge on method transfer: a sectoral system of innovation approach

Year/Útgáfuár: $\quad 2013$

Version/Útgáfa: $\quad$ Pre-print (óritrýnt handrit)

\section{Please cite the original version:}

\section{Vinsamlega vísið til útgefnu greinarinnar:}

Hvannberg, E. T. (2015). Identifying and explicating knowledge on method transfer: a sectoral system of innovation approach. Universal Access in the Information Society, 14(2), 187-202. doi:10.1007/s10209-013-0340-1

Rights/Réttur: $\quad$ C Springer-Verlag Berlin Heidelberg 2013 


\title{
Identifying and Explicating Knowledge on Method Transfer: A Sectoral System of Innovation Approach
}

\author{
Ebba Thora Hvannberg \\ University of Iceland \\ Hjardarhagi 2-6 \\ 101 Reykjavik \\ ebba@hi.is
}

\begin{abstract}
With the advances in information technology and its increasing impact on humans and society, there has been an expanding need to spread knowledge from domain to domain. This need is not least in the area of human-computer interaction, which includes a rich culture of carrying out usability evaluations in many different domains and technology platforms. This paper aims to show how transfer of methods takes place, by explicating and formalizing the process. It will contribute to the quest for knowledge on the constituents of the process of transferring methodological knowledge and their relationships. A sectoral system of innovation approach is used to analyse the constituents of a selected sector, crisis management, where training is essential and which is rapidly adopting technology for operations and training. Two case studies are described where heuristics evaluation and user testing were applied on simulation software that allows training for crisis management. The analysis results in a process model, describing the transfer of methodological knowledge within the sectoral system of innovation framework.
\end{abstract}




\section{Introduction}

Learning or studying phenomena takes place in a certain situation and when these phenomena are placed in a new situation transformation of knowledge takes place from the old to the new. Transfer of knowledge is researched in many perspectives, e.g. transfer of training to practice [1], transfer of knowledge from university to industry [2] or transfer of knowledge from one domain to another [3]. With the advances in information technology (IT), its increasing impact on humans and society and its requirements increasingly formed by a domain [4], there has been an expanding need to spread knowledge from domain to domain. This need is not least in the area of human-computer interaction, and we have seen examples involving design [5] and evaluation [6]. Transfer of knowledge appears in miscellaneous instantiations and can be of varying degrees. Knowledge can be adapted to new settings, technologies can be adopted by companies, and in some cases the targeting context is so different from the original one that it calls for knowledge transformation. Shepherd and Bleasdale-Shepherd [5] explicate a framework, design-by-adaption, with a case study that shows how the design of a video game can be transferred to visualization of geographical data. Heuristics evaluation is an expert review method proposed in the early nineties to evaluate the usability of software systems [7], and has been applied in many domains, sometimes unchanged but sometimes altered. One of many examples where the heuristics have been changed is for Virtual Environments [6], where the original Nielsen's heuristics have been adapted and additional heuristics based on knowledge specific to virtual environments has been adopted. Although a number of such modified heuristics evaluation methods have been proposed, there are few studies on their uptake [8] and little is known about how the new methods are devised. For design and evaluation of software systems, countless methods are applied. It has been postulated that these methods can vary from one sector to another [9] or resources applied differently depending on the domain [10].

Regardless of what type of knowledge is transferred it entails innovation. Innovation is about turning a new idea, product, process or service into an exploitable entity available to markets or society. Understanding the drivers of transfers and the environment can help us understand how the 
transfer is carried out. It has been found that learning and technological contexts define the boundaries of what can be achieved and provide a motivation for innovation. Opportunity and appropriability conditions are believed to affect innovation, together with technological knowledge and the attributes of the relevant knowledge $[11,12]$. The sources of innovation and the tools of appropriability are supposed to differ across sectors, as summarised by Malerba [13] with reference to Rosenberg [14], Mowery and Nelson [15] and Pavitt [16]. From analysing sectoral patterns of innovation, Pavitt concluded that there are two central attributes of innovations. One is that knowledge is not general purpose and easily transmitted but appropriate for specific applications by specific firms, conditioned by what they have been able to do in the past. The second one is that there is a large variety between sectors on how important a product and process the innovations are. In addition, the size and pattern of the sectors' technological variations differ. Despite all this, there is some convergence. Continuous process industries tend to focus on their process innovations, driven by suppliers of equipment, but others, e.g. chemicals, electrical, mechanical and instrument engineering, focus on product innovation [16]. Based on this, Pavitt [16] proposed sectoral patterns of technical change which has three categories, supplier dominated, production intensive and science-based sectors. He characterized the difference between these classes by different technological trajectories: source of technology, users' needs and means of appropriating benefits.

Malerba [13] put forward a definition of a sector as being a set of actions which are unified by related product groups for emerging demand and which share basic knowledge. He formalized the difference across sectors by proposing a sectoral system of innovation approach which is inspired by evolutionary theory and the innovation system approach. Evolutionary theory emphasizes operators of change as creation of variety, replication and selection, but bounded by the technology, knowledge base and the organizational context [17]. For example, evolutionary theory has been applied to investigate the evolution of software based on the fundamentals of variation which are triggered by mutation, using the operators of adoption, selection and retention [18]. Malerba's [13] second inspiration of a sectoral system, the innovation system, considers innovation as an iterative, 
collective process which is interactive among a variety of actors. Actors and networks, among them, knowledge, technologies and institutions form parts of a sector. The sectoral system of innovation framework highlights five aspects: supplies, demands and markets in the innovation process; firms and other types of agents such as universities; non-market and market interactions such as exchange, co-operation, competition and command; and a process of transformation of the sectoral system instead of static sectoral boundaries [13]. Perhaps, it is not least this last aspect which is interesting for our work, i.e. that a sectoral system changes and transforms, even creating emerging new sectoral systems evolving from several existing ones. Underlying the five aspects above are three main building blocks of a sectoral system. The first one is knowledge and technology, the second one, actors and networks and, the third, institutions. Malerba validated his proposed model by analysing five major sectors with respect to innovation. The five sectors, pharmaceutical and biotechnology, telecommunication equipment and services, chemicals, and software and machine tools, were selected because change in technology has been rapid and innovation has played a large role in their growth. Using an analogous methodology we aim to analyse the crisis management sector, but focusing on case studies that show how it has or needs to innovate evaluation methods. To explicate how the transformation method has taken place, we have attempted to model it within the sectoral system of innovation framework as depicted in Figure 1.

For the discussion in this paper, it is useful to postulate that development activities applying various design and evaluation methods are included in the set of actions that constitute a sector and help develop related software products for emerging demands. In analysing these actions we will study how the development activities are specific to sectors. A major driver of advancing and applying evaluation methods is the need to improve the development process, resulting in more efficient software development and better and more valuable products than possible before. Using the aspects of a sectoral system [13], methods are developed and used by actors, i.e. practitioners, scientists, firms, universities and their networks. The Twintide project (http://www.twintide.org/), within the COST framework, is an example of a network where people collaborate on researching 
methods transfer between sectors for the design and evaluation of interactive systems. In addition to the individuals of Twintide, their universities and research institutions form a network of collaboration. When participating in conferences or standardization bodies, the Twintide project or its members link to other networks which exist formally or informally. The knowledge and technologies of evaluation methods are general or specific to sectors, e.g. games, learning, health and security. The technologies applied by evaluation methods vary from simple audio recording and automatic analysis of usability to eye tracking. The software's technological aspects have a large impact on evaluation methods for interactive systems. Thus, there are evaluation methods for mobile systems, web systems and virtual environments [6]. Another side, the social side, as in collaborative systems, categorizes evaluation methods [19]. Depending on the goal of the analysis, sectoral systems can be defined broadly, e.g. by agriculture, construction and software, and narrowly by product segments such as databases. The core of a sectoral innovation system is the demand for a product and its evolution. Demand is not seen as generated by a homogeneous user group but by a heterogeneous group which interacts internally and with the producers.

Advances in domains [20], technologies or systems, e.g. complex systems [21], has continuously driven the evolution of methods, but how this takes place has been less researched, i.e. what are the processes of transfer in the innovation system as a collective, interactive, iterative course between actors. To motivate identification of this knowledge we will present two case studies from evaluation methods of interactive systems of crisis management training. Crisis management is a complex sector drawing knowledge from a number of organizations and is under pressure to deliver high quality service in situations where lives and properties are at stake. The sector is advancing, for example with increased transportation of people and goods, and crisis management in the area is increasing in scale and scope while simultaneously benefitting from advances in IT to support operations. Since actors cannot rely on operations for their training, planned training is of utmost importance. Rooted in this demand and because of the opportunities in IT, there is on-going development on how training is carried out. By studying this complex sector that draws knowledge from different angles 
and is evolving, we think that we can learn substantially about the evolution and innovation that takes place. We will contribute to the study of evolution of methods by presenting guidelines for identifying and describing components of methods transfer. Only by learning how the transfer of methods happens are we able to explicate it and formalize it, and propose how the transfer can be improved. Implicitly, with this research, we hope to contribute to the quest for knowledge on the constituents of the process of transfer of methodological knowledge (i.e. parts of the procedure) and their relationships within the sectoral systems of innovation approach. 
Table 2 shows the structure of the sectoral system of innovation which was used to identify knowledge on transfer of methodological knowledge. The structure shows the three basic building blocks of a sectoral system and two dimensions describing its transformations, which can be described using evolutionary theory and actions of innovation. We hope that having analysed the crisis management sector, a complex sector potentially rich in innovations, our guidelines will also apply when describing transfer of methods in other sectors.

The next section starts by describing crisis management and its training. After describing crisis management as a sectoral system of innovation, the section describes two case studies of transferring two evaluation methods, heuristics evaluation and user testing. Section three on methodological conclusions formalizes through abstraction the process of transferring method knowledge between sectors. Furthermore, it describes how this model can be general for others wanting to transfer methodological knowledge.

\section{Crisis Management - A Sectoral System of Innovation}

\subsection{Crisis Management and its Training}

Crisis management is about responding to a mass-casualty incident by rescuing, attending to casualties, transporting resources to the scene of the incident as needed, and transporting casualties safely to hospitals or other institutions where they receive medical treatment according to certain priorities. The overall objective is recovery of normal operations while minimizing the effect on people and property. Crisis management involves work in the field, rescuing, caring for casualties, and transporting them to hospitals and, in command and co-ordination, managing and ensuring that resources are available, responding to changing situations and mitigating risks. Since the necessary crisis response often occurs away from hospitals or other medical institutions, one of the challenges for actors is that they lack access to the same resources as they have in normal surroundings and the 
need for resources can be sudden and overwhelming. This calls for strict prioritization and utmost organization which is implemented with command and co-ordination in a certain hierarchy which can vary between nations [22]. Inevitably, communication and flow of information is an essential part of crisis management. Another characteristic of crisis management is the involvement of stakeholders from several organizations such as police, fire and rescue groups, medical teams, the Red Cross, local, national and international authorities.

Crisis management is organized according to a prescribed plan, e.g. an airport plan, which needs to be trained for regularly according to regulations specified by international authorities and implemented by national ones. Training in the implementation of such a plan is required periodically and can be specified as a whole task and part task [23]. A whole task is one that takes place in a real environment and includes the problem, the tasks to solve the problem, operations of the tasks and actions comprising the operations [24]. The training is carried out in various forms. One is a real-life exercise requiring a large number of participants from all stakeholders; another one is a part task exercise; and a third one is a table-top exercise for exercising logistics, command and communication. An important part of such exercises is to set them up, stating their learning objectives, creating realistic scenarios of different difficulties, and after the training to review its outcomes, pointing out problematic areas and successful training.

Because of the strict training requirements that are expensive, there is a constant search for efficient means of training. With the development of information technologies there has been research on crisis management training using the concepts of serious games, for example in virtual environments [25]. Intrinsic parts of such training systems are various advanced technologies including interactive technologies, instructional design [26], intelligence of actions of avatar players, intelligence to create random, variable events or stimulus [27], and random consequences of actions. Creating such scenarios requires a powerful training planner and a tool for carrying out an effective 
after action review [28]. Such an after action review is a valuable input to continuous improvement of operations and training.

\subsection{A Sectoral System of Innovation for CM}

Prior to discussing case studies of the transfer of methods to the crisis management sector, we describe its sectoral system of innovation (Table 2). The sectoral system for crisis management will be described from the perspective of its building blocks, i.e. knowledge, technologies, actors, networks and institutions. As an integral part of this system, training is discussed in terms of each of the aspects. We conclude the section by discussing crisis management in more detail from the perspective of evolutionary theory and the innovation system.

The knowledge base of crisis management has developed since its onset at the beginning of the twentieth century [29], formally established by Lindemann [30]. Knowledge has developed most closely within a national system of crisis management and within a specific sector, such as transport, or even more narrowly in air, maritime, or terrestrial transportation. In some cases, knowledge develops across national boundaries, such as when the Eyjafjalla Glacier erupted in 2010 and thus affected the airspace of Europe and beyond, inhibiting air transport within and to Europe [31,32]. Although it affected people and property, fortunately this crisis did not cause any deaths, but it exemplifies well a case where national institutions in many countries had to respond to and resolve a crisis. This motivated research in the area of advancing knowledge and, as in the case of the Eyjafjalla Glacier eruption, it is likely that knowledge in the sector will progress with each new crisis.

Various technologies are a part of the different disciplines of crisis management, e.g., fire, rescue and medical aid. Communication technologies are an essential part of command and co-ordination and need to be reliable and widely accessible. Implemented with GPS technology, tracking resources, whether they are vehicles or people, can be of great help for managing logistics. Information technology has entered command centres via databases of resources, tasking of responders, maps and electronic whiteboards. General technological advances and the need for improvements of 
operations are the drivers of technology progress within crisis management. The technological advances are constrained by the contexts of crisis management, which is partly in the field, or in settings which are without the necessary infrastructure.

Knowledge of training in crisis management is an aggregate of the crisis management discipline and instructional design. Instructional design can cover a broad area, including technological advances that offer more efficient training. Training in crisis management simulators, set in virtual environments, is one such example. One of the challenges of these instructional designs which develop in parallel to knowledge of crisis management is to keep up with the technological and knowledge advances achieved in crisis management.

The actors of crisis management are members of different professions, including various disciplines, crisis medicine, crisis counselling, fire engineering, air traffic control, rescue and search and logistics. Varying between countries, volunteers working alongside professionals form the set of actors. Members form networks, but mostly within their own professions, except at the command level, where there are likely to be opportunities for network forming. Networking takes place between scientists, crisis management operations, instructors and firms offering technological systems and are materialised at conferences or other similar venues.

Institutions of crisis management instigate rules and regulations regarding quality and set the framework for response. National institutions especially play a large role and, to a lesser degree, international ones. In the area of crisis management there are communities such as Information Systems for Crisis Response and Management, ISCRAM (http://www.iscramlive.org/portal/). These institutions are likely to provide opportunity for knowledge exchange and interdisciplinary interaction.

Crisis management, as a sectoral system of innovation, evolves via learning from crisis operations and training. After-action review is a large part of the crisis management culture and motivates 
evolution through learning. Hence, there is a selection of methods and processes, transfer from science and replication from crisis management in different areas, e.g. transport or chemicals, or disciplines which constitute crisis management. Variety creation may take place in different contexts of crisis management, e.g. small or large operations, and from offerings of different technologies. The innovation process is highly iterative and collective through interaction between different organisations and actors. During crisis response actors from organizations collaborate closely and a national system of innovation is prevalent. In research of software applications of crisis management training we have seen examples of replication and adaptation of training simulators from other areas, e.g. from games [33]. In crisis management there is high demand for innovation, created by users, by national systems, and by stakeholders who drive the quest for continuous improvement. Regardless of operations or training, learning from past experiences is a major motivation for this innovation. Every crisis or training activity brings about a number of issues that need to be addressed in the follow-up [34].

To research and develop technologies and methods for crisis management training with the aid of software, the CRISIS project (http://idc.mdx.ac.uk/projects/crisis/) set out to develop an integrated training environment for field and command exercises. The objective of the project is to include a planner of exercises, a training module and a tool for after-action review. The technologies include innovative user interfaces, decision support, instructional design and knowledge extraction. Twelve training gaps and requirements using the 4C/ID instructional design [35] have been identified as a result of a thorough requirements analysis which entailed interviews, questionnaires and observations at three different end user sites in as many countries, spanning air and train transport.

In the next two sections we give examples of methods transfer to the crisis management sector and analyse them with respect to a sectoral system of innovation, emphasizing building blocks and the process that was needed to transfer the methods. Both examples describe case studies of methods that are used to evaluate the usability of a prototype of the CRISIS system. The methods 
are heuristics evaluation and user testing. What motivated us to use these examples is that they have been used for several decades by practitioners [36,37] and studied extensively by researchers [38]. They have been used in many application domains. From the perspective of the initial proposed versions of these methods, they have been adapted and they have evolved to what can be seen as new methods, sometimes radically different from the original versions. However, to the best of our knowledge there have not been any studies where components of sectors have been analysed for the variability between sectors with respect to development activities, specifically, and the evolution of methods.

\subsection{Heuristics Evaluation of CRISIS - A Case Study of Methods Transfer}

\subsubsection{Building blocks}

Evaluation methods for interactive systems span a wide area from several disciplines, all aiming to evaluate human-computer interaction with the objective of improving the system's user interface or assessing its conformance to some quality, for example usability, user experience, accessibility or safety [39]. One can argue that evaluation methods of interactive systems constitute its own sectoral system of innovation, where the products are evaluation methods with demands from interactive designers and product developers who share some basic knowledge. However, since the intricate sides of domain knowledge, here crisis management including training, have such a vast impact on the usability of professionals' work [40], we claim that they cannot be studied in isolation. Thus, we opt to view the evaluation methods of interactive systems as a part of the crisis management sectoral system of innovation. It follows that evaluation methods and their applications are included in the set of actions that constitute the crisis management sector. Whereas in the previous section we mostly excluded development activities as a subset of action of crisis management, in the forthcoming and the next case study, we add these and look at their integration with the main actions. In our description of the sectoral system we have made this assumption by including knowledge, technologies, actors, networks and institutions of the developers of the products, 
regardless of their types, e.g. airport plans, communication systems, resources databases, resources trackers, learning objectives, and instructional designs.

As introduced above, we set out to evaluate the interactive aspects of a Crisis Management Training Simulator (CMTS), i.e. its usability, early in its developmental phase. In the search for a method of evaluation we decided to use a well-known method called heuristics evaluation[41]. It is an inspection method, requiring experts in interactive technologies and usability. It is based on ten heuristics which are applied as the user interface is examined, often while carrying out a predefined set of tasks. Double specialists, having expertise both in usability and the particular kind of interface being evaluated, do better. The issue of expertise and evaluator effect has been much researched, although more apparent in user testing [42]. While Nielsen [43] only discussed experts having knowledge in a particular user interface, Folstad and colleagues have researched a related type of expertise, i.e. those having knowledge in the work domain [44]. The underlying motivation is still the same, developing a method that is efficient and produces an outcome with the highest validity and persuasion. In heuristics evaluation, an inspector examines the user interface and records any usability problems and labels them according to one or more of the heuristics. If more than one inspector carries out the evaluation, problems are consolidated into a list of unique problems. The frequency of a problem gives information on how many inspectors uncovered it. Sometimes the severity of each problem is rated, from minor to major, depending on the impact it is expected to have on the user. Besides rich knowledge on the original method of heuristics evaluation, there have been many derivatives developed with different objectives. One is to make it more efficient, such as Participatory Heuristics Evaluation [45], HE extension [46] and (MOT) [47]. Another motivation is to change the perspectives of evaluations to, for example, user experience [48]. A third goal is to create heuristics sets that are specific to particular application domains. Ling and Salvendy [49] have provided a comprehensive analysis of the different derivatives of heuristics evaluation. 
Searching for a suitable heuristics list and resources to evaluate an early prototype of CMTS we found a heuristics list designed for virtual environments which we label S\&G [6]. Hvannberg et al. [8] described in detail the exploitation of S\&G and its application to CMTS. Below, we describe how the method's transfer to crisis management has taken place.

Using the framework of sectoral systems of innovation to describe heuristics evaluation as a set of actions in a sector, we recognize that knowledge of heuristics evaluation methods is quite rich. It has been developing since its introduction in 1990 [41] and outlived many other usability inspection methods [50]. Its evolution has been towards more efficient methods and to specialized fields for different sectors and interactive technologies such as virtual environments, games, health, web and mobile systems. Although problems and their ratings can be stored electronically, the technological settings of heuristics evaluation have been minor and, mostly, the evaluation is based on manual inspections. The actors in the sectoral system of innovation are developers of interactive systems, designers and evaluators, and the networks tend to be broad and to include other evaluation methods. Institutions are rather scarce, but standardization bodies have built a foundation by specifying quality frameworks and development processes for interactive systems [51,52].

\subsubsection{Transfer process}

Having looked at the three building blocks of a sectoral system of innovation, we now turn to examining how it has been transformed, explicating the innovation system and using the operations of evolutionary theory. When the S\&G list [6] was used to evaluate the CRISIS prototype two lists of tasks were used for two collaborating roles that are typical in crisis management. To help inspectors learn and be in line with the heuristics list a set of conformance questions was designed [53]. These questions were meant to guide inspectors to achieve accurate results because of the complex heuristics list for a virtual environment. An example of such a conformance question for the heuristics of Clear turn-taking: Does the system indicate when taking control of the VE and when this control is returned to the user? (e.g. are conventions of turn-taking in conversations followed?). 
Hvannberg et al. [8] concluded that while S\&G was useful, only to a small extent did it address other more complex aspects of crisis management, such as collaboration, oral communication, the effect of noise, and learning which is fundamental to crisis management. Hence a heuristics list that is more closely adapted to the sector needs to be developed with other types of heuristics addressing those aspects would be needed. A valuable resource could, for example, be heuristics for co-operative systems, as has been proposed [54], which addresses the mechanics of collaboration, including verbal communication. Similarly, the literature shows that there are design guidelines or heuristics on education technologies [55].

The third building block of a sectoral system of innovation is the institutions. Evaluation methods are not rich in institutions except for the quality models that underlie them $[56,57]$. Cursory research has not revealed institutions that are sector specific for evaluation methods for crisis management training, but in other domains such as the medical domain [58] analogous institutions may set specific requirements on evaluation. There are several conferences on human-computer-interaction and specific ones on virtual environments and games. To an extent these include tracks on usability evaluations, but there is no specific conference focusing on the topic alone.

To help us understand the innovation process, we turn to analysing interaction, iteration, actions across disciplines, and learning. Hvannberg et al. [8] did show that the uptake of specialised heuristics lists for a virtual environment is slow, but that the variety of sectors in which they are applied is moderate. The transformation or the innovation that occurred from Nielsen's list [7] to Sutcliffe and Gault [6] can be seen as a collective process, using knowledge from different theories and the work of various scientists. Interestingly, this transformation process was similar to the one which was applied when Nielsen proposed the original heuristics list.

By looking at how the S\&G list has been exploited, a number of interactions between actors can be seen. One is a relationship between evaluators and designers [59]. Until now, there has been no investigation on how the resulting problem list, using this slightly evolved method, was perceived by 
developers of the prototype, but interaction with other actors (e.g. product designers of crisis management) in the sectoral system of innovation is essential so that we can see the persuasion and downstream effect of the uncovered problems [60]. Another type of interaction is between evaluators of different qualities. For example, in crisis management training it is essential to evaluate the product's usability and its training effectiveness, including its return on investment [61].

The conclusion of Hvannberg et al. (2012) is that in using the S\&G list, researchers have not used it unchanged but evolved it further by selecting items from the heuristics list. When we inspected how it had been applied, we noticed that the uptake of a method entails some adaptation. Undoubtedly, there are iterations of methods development, but probably with long and few cycles. This means that the pace of change is slow, but speed of transformation is not an attribute in the transformation process. This attribute may be interesting to research with the aim of adding it to the transformation process model (see Table 1).

Next, we give a brief analysis of the operations of the evolutionary theory. Apart from Hollingsed, Novick [50] there is little evidence if practice is selecting one inspection method over another. There seems to be considerable variety creation through mutation, driven by the needs of domains, and in part the conceptual and technological aspects of the interactive systems under evaluation. Technologies supporting the method itself do not seem to be a driver for innovation or transfer.

The above analysis has shown that the characteristics of the crisis management training sector, as we have defined it, influence the transfer of the heuristics evaluation method. Many of these characteristics are not unique to the crisis management sector and can be applied elsewhere. For example, collaboration, verbal communication, soundscapes, virtual environment, and educational technologies are all (heuristics) technologies that can be applied in other sectors. One of the challenges we have experienced is to find ways to consolidate knowledge of heuristics evaluation resources, e.g. performing a composition of heuristics list to meet the need of the sector. Another challenge is to include domain and user interface technology expertise in the evaluation. This may 
raise the need to better formalise domain knowledge. No doubt there could be further opportunities for advancement in heuristics evaluation to tailor to the sector.

\subsection{User Testing of CRISIS - A Case Study of Methods Transfer}

\subsubsection{Building blocks}

This section describes how user testing has been carried out to evaluate CMTS. The basis for this evaluation is a traditional think-aloud user test [62] where users are given tasks, they think aloud while carrying out the tasks, and an observer notes any problems. Before taking on this evaluation, we searched for different derivatives of this method that would be suitable for collaborative systems. Of course there are many other aspects that had to be taken into account such as the domain of crisis management, training and conceptual aspects, serious games, and technological factors such as verbal communication in a noisy virtual environment. We decided to use a collaborative systems framework [19] to help us choose an evaluation method. The framework is based on two dimensions. The first one includes six variables. Three variables are associated with the goals of the evaluation as described by McGrath [63], who states that research in social and behavioural sciences involves somebody doing something in some situation. The variables are generalizability of the evidence over a population of actors, precision of measurement of the behaviours, and realism of the context. Three variables describe factors that prevent evaluators from running very costly evaluations, i.e. specifying invested time for evaluation, the scope of the system being evaluated and its detail. The second dimension is described by human performance levels, i.e. role-based, rule-based and knowledge-based performance, which were adopted from Reason [64]. For our evaluation, we decided to focus on realism, end-user evaluations and usability. Rule-based performance includes co-ordinated activities that are carried out with decision making by people but within the constraints of a specific plan. Since crisis management training can be considered as composed of planned tasks with mixed control, where the environment (e.g. time of accident, resource availability) influences the control and decisions of crisis personnel, we found that activities were best described by rule- 
based performance. Using Antune et al.'s [19] framework we decided to use Groupware Observational Testing (GOT) [65]. Three pairs of participants playing two roles participated in the evaluation. Altogether 14 tasks were designed to make up a realistic scenario for these roles. Each pair was evaluated separately, with one evaluator observing each role. Audio was recorded and the screen was captured with video. Evaluators noted down any problems. Users were not asked to think aloud, but at the end of the evaluation two questionnaires were conducted. The first one asked users about the effectiveness, efficiency and satisfaction of each task, and the second one was a Systematic Usability Survey (SUS) [66].

Research on user testing has been extensive, focusing on different aspects, such as evaluators' efficiency and their skills, comparison with other evaluation methods [67], protocols to extract data [68], the place of the user testing, e.g. in the lab, in the field, local or remote, and analysis of its results [69]. Knowledge coming out of this research is often targeted for practitioners. The need to study the practical aspects of carrying out user testing in industry is visible in the literature, such as training of usability practitioners [70], carrying out observations with the think-aloud protocol [71] or analysing data [72]. The topic of user testing for specific contexts, whether they are technological, sectoral or otherwise, has been prominent in the literature. Examples include user testing of mobile platforms and virtual environments. The range of disciplines that use user testing is countless, but the literature describes experiences in games, educational technologies and health. The list of disciplines may be affected by the researchers' need to investigate how user testing has to be adapted to the relevant areas or it may be affected by the emergence, popularity and size of these disciplines.

For user testing it may be hard to distinguish between knowledge and technologies, since much of the knowledge on user testing, as we have described above, is on methods or, at least, ways to carry out user testing and thus can be categorised as technologies. If we narrow the discussion on software or hardware tools for user testing, there has been less development than on the methods. 
Nonetheless, there have been advances in technologies that can be used for observation such as video, eye-tracking and psychophysiological meters. Hand in hand with technologies for gathering observational data, there have been developments in their analysis such as video data [73] and automated content analysis methods [74].

Actors of user testing are usability practitioners, users, software developers, method and technological developers. Actors also include the buyers of the software and other stakeholders involved in its deployment. As we mentioned above when discussing heuristics evaluation, networks tend to be broad and include bodies interested in any type of evaluation methods or interactive systems as a whole.

\subsubsection{Transfer process}

The number of methods available for collaborative systems shows that there is considerable variety which has evolved over more than two decades [75]. Above we used the selection operator from evolution theory to determine which method to use. The question remains, and is not addressed in this paper, whether industry or any one sector is selecting one method over another to be more suitable and thus potentially resulting in a method which is best. Although the collaborative framework does not explicitly aid with the selection of the fittest, as in evolution theory, it may help in reducing the heterogeneity of methods [13].

The SUS method has been used extensively [76] and some derivatives have been designed to help practitioners interpret the results of individual questions [77]. Since, we were only interested in the one value score of the questionnaire, we used it in its original form. The questionnaire asking about effectiveness, efficiency and satisfaction of each task, mentioned previously, was used differently for this evaluation than we had done in earlier studies. In those, we asked these questions after each task. Since probing users after each task would have broken the flow of training, we decided to ask users about all the tasks after the session and, thus, relied on their recollection of 
their performance and experience. Probing users in a reflective instead of concurrent manner has been investigated [78].

One of the largest factors in the transfer was how tasks were selected for the user testing. Several aspects needed to be taken into consideration, which are different than previous experiences. First was the crisis management domain, second the training, third the collaboration between trainees, and fourth the technologies used. Instead of creating a set of loosely connected tasks, a scenario including two collaborating trainees needed to be designed where the order of tasks was important. We can compare it with going from writing a shopping list of tasks, with some connection between the tasks, to writing a theatre play script. This case study agreed with previous research which has shown that task selection in complex domains is particularly challenging $[40,21]$. The task selection was guided by the domain and the objectives of the evaluation. The overall objective was conformance to the domain and usability. Sub-objectives included research on users' response to noisy environments, sound as a tool for situation assessment and navigation and the realism and usability of verbal communication. Thus, we wanted to see if the soundscapes proved real, i.e. whether noise from fire, fire trucks, helicopters or people's chatter was real to users. By this we mean whether sounds helped users to assess situations such as their urgency, whether they helped users to navigate to or from the accident scene, and whether noise proved to be disturbing while talking across telecommunication channels. Since we went for overall realism instead of precision it proved challenging to include tasks to test users' perception and response to sound, especially since we did not include any objective instruments to measure these. Measures could have been, for example, tracking distances from objects or analysing a higher voice pitch when close to a noisy source. By designing tasks which required verbal communication in and outside of noisy situations and navigation to noisy environments we hoped that this would allow us to observe users' behaviour and assess their perception and experience. For example, we asked responders to go to the accident scene (e.g. guided by the noise of fire engines or fire), triage casualties and report numbers (still, in a noisy environment) to an on-scene commander who was in quiet circumstances. 
The method application leaves much room for improvement, hopefully motivating future transfers of evaluation methods for this sector. There were two major concerns. One concern was the lack of good instruments to assess sound perception and verbal communication usability. The second one was the use of prescribed tasks, or scripting, for evaluations. This evaluation showed that reliance on these prescribed tasks affected users, but this is a problem in any scripted training where fidelity of training [79] is less than in a real situation. Instead of reacting to the situation at hand, trainees start to follow a script too closely. We conclude that for evaluation methods to evolve and to meet the multifaceted challenges of technology products for a domain, an interaction needs to take place between experts in the crisis management sector, in the evaluation methods subsector, in the fields of training simulators, games, sound and communication. Task selection alone is not a sufficient resource for adapting to a sector. Instruments for data gathering and advanced analysis are important too [80].

\section{Formalizing transfer of methodological knowledge}

\subsection{Sectoral System of Innovation to describe transfer of methodological knowledge}

This research stipulated that the sectoral system of innovation with its building blocks and transformation process could serve as a framework for describing the transfer of methodological knowledge, especially knowledge on evaluation methods. Using the framework, two case studies of transferring evaluation methods to the crisis management domain were studied. The next two sections summarise the results in terms of the basic structure of a sectoral system of innovation (Table 1) and discuss to what extent the findings of this research study are generalizable to other sectors or other evaluation methods.

By analysing two case studies of method evaluation within the framework of a sectoral system of innovation for crisis management, we have laid the ground for guidelines for identifying and 
explicating their transfer to a new domain. In the examples of transfer of evaluation methods we analysed the knowledge, technologies, actors, networks and institutions which were the constituents of the sectoral system of innovation in which the methods resided. The transformations of the evaluation method, being a part of a sectoral system, occur via several operations, such as selection, variety creation, composition, adaptation and replication in a collective process operating between the constituents in an interactive and iterative manner.

What were the constituents of the process of transfer of methodological knowledge? The recognition and description of the demand that stimulates innovation is of utmost importance. The case studies showed that knowledge of methods develops in two directions: towards improved efficiency and broader contexts. In the case of evaluation methods, we concluded that software and hardware technologies as tools for these methods develop slowly. Whereas the $\mathrm{HCl}$ community has long promoted user-driven methods, the sectoral system of innovation encourages defining a sector which allows a broader perspective of actors, including, for example, various domain experts, methods developers and technology developers. Collaboration in networks such as Twintide has been encouraged, but the sectoral system of innovation approach encourages an advance to another level including a broader group of actors, though within the relevant sector. By describing crisis management training as a sector and within it two case studies of the application of methods of evaluation, we feel that we have demonstrated that this framework can be useful and encourage methods developers to take a broader perspective beyond design methods or technologies, but also a more focused view on its building blocks, e.g. actors, interactions and networks, and the transfer process.

The building blocks of the sectoral system of innovation, i.e. knowledge, technologies, actors, networks and institutions, are not new in systems development. Domain engineering, for example, emphasises knowledge and technologies [81]. Some of these terms, such as actors, are often confined to users. However, what this study has analysed is the domain knowledge and the 
difference in methodological knowledge between sectors and posits that the interaction of the two will help the transfer to new sectors and identify gaps which can stimulate innovation. Furthermore, this process can be generalized to other sectors. Whether these building blocks are the only ones needed, we cannot assert. There may be others or it may be useful to subdivide some of them. Future case studies could help shed light on this. Table 3, which is a summary of the operations of evolution applied in the two case studies, shows that all operations were applied. In both cases notable change occurred as the methods were moved to the domain of crisis management training. The results of the analysis shows that while transferring the methods, additional needs were identified, which can be a stimulus for further transfer of the methods. This gap can be used as a motivation for further innovation of the methods. It is apparent from the case studies that knowledge had changed and even the technologies utilised. Knowledge was transferred from other areas. With the usability evaluation of the crisis management training simulation software, new actors enter the sectoral system, and with the CRISIS project new networks are formed. Changes in institutions may take longer.

We cannot see any characteristics of the crisis management domain that prevent us from generalizing operators of methodological knowledge to other sectors. Furthermore, the operators seem to be applicable to other evaluation methods, but they may be used variably. For example, where there is a smaller set of method variants there may be less reason to select a variant. As we have stated above, only further case studies of the transfer of methodological knowledge will tell if the evolutionary theory proves sufficient to understand the transfer. For example, in our case replication was not used, but adaptation was added to the list of operators. In another example, that of writing a scenario of selected tasks (e.g. a theatre play script), proved difficult and called for a new resource and turned out to be too hard to label as merely selection.

\subsection{How can transfer of methodological knowledge be achieved}


While we discussed the components, i.e. the building blocks and the operators, of the sectoral system of innovation in the previous section, we will now turn to formalising how these are used to create a modified sector.

It is unlikely that the transfer of methodological knowledge will consist of only a single step operation but rather of several subsequent or parallel steps and, perhaps, converging to a method which is acceptable to many. Although the transfer process may be specific for certain method profiles, it is thought to be rather abstract. We have seen that for heuristics evaluation it may include the evolution of the heuristics list, refinement of how each item on the list is specified, or the resources that are used, such as the types of tasks or number of inspectors used. Figure 2 shows the transfer process within the sectoral framework of innovation. At the onset of the transfer process, the actors will pull knowledge and technologies from different areas, such as software technologies, crisis management (e.g. organizational knowledge), training and design and evaluation. The transfer process may consist of several parallel processes where all actors or a subset of actors work together on evolution. This process is started by one or more demands, which we label stimuli, to start the process. The stimuli to transfer methods can be different, including increased efficiency for crisis management or evaluation methods or exploitation of the training software. As the actors cooperate and collaborate they are bound to pull in further knowledge from peripheral areas that are relevant for the work and are not yet part of the sector. When the actors are working together on the transformation they may form networks or communities of practice [82]. When this process includes several iterations, institutions, actors or institutions may change, emerge or disappear.

The transfer operations may be complex, and even more so the interactions between actors. The example of the specialised heuristics list for a virtual environment entailed a detailed investigation into different adjacent research areas and it was not validated until it could be used in different settings of virtual environments. Although the overall stimulus for transfer may be assumed to be a 
demand by evaluators or the insight of researchers, they may be challenging to determine. Each transfer operation may be assumed to be expensive, requiring thorough research studies.

To pull together the different knowledge emerging from research and practice on usability evaluation and its evolution for different sectors, an amalgamation empowered by a large institution may be needed. Institutions setting norms for development methodologies of software are thought to be rather weak but those for crisis management as a whole are much stronger. The question is how that strength interacts with and affects its various components, such as software products for crisis management training and its development processes. On one hand there is a demand from the actors, networks and institutions managing a crisis to carry out effective operations. This is likely to find its way to product developers; they compete with other firms, but will they choose to be product or process focused. If they are process focused, i.e. more inclined to think about the methodologies they use during development including evaluation, they see this effort as likely to return an investment. This force will push development of methods forward and encourage innovation, e.g. through transfer. On the other hand, if they are product oriented, they are unlikely to have a rich knowledge of methodologies; this shortage may cause stagnation in the evaluation area. Parallels have been seen in the standardization work of software quality where there are two different forces, i.e. product standards and process maturity standards (CMM) [83], that have been compared [84].

Although based on an analysis of different sectors other than crisis management training or the software sector, it is interesting to look at Pavitt's [16] sectoral patterns of technical change and the conclusions he made from the analysis of suppliers of production equipment (mechanical, instrument engineering), producing sectors (e.g. food, shipbuilding, motor vehicles) and sciencebased sectors (e.g. producing chemicals and electrical/electronic products). Whereas innovating firms in the first category are small and diversifying technologically little, the innovating firms in the second category are large with a high level of vertical technological diversification and make a comparatively large contribution to all the innovations of their principal sectors of activity. An 
analogous example from the interactive systems industry is that firms producing a software component for an interactive system tend to be small, diversifying little technologically, whereas firms developing innovations for software processes (such as Integrated Development Environments including User Interfaces) are likely to make a large contribution to the principal sector of activity. In the first case, the users and others outside the sectors are those making significant contributions. The innovations in the second category produce their own process technology and they make relatively large contributions to all the innovations produced in their principal sectors of activity. In contrast, the firms in the first category produce a relatively high proportion of their own process technology, but the main focus of their innovative activities is the production of product innovations for use in other sectors.

If we draw parallels with the crisis management sector we should expect that this sector, as a production (or service) sector, will mainly innovate within the sector but in order to make a relatively high level of vertical technological diversification into equipment related to their own process technology. On the other hand, a company within the evaluation methods subsector has the potential to diversify through its large customer base of different industries, including crisis management. A firm focusing on evaluation methods has specialized knowledge in evaluation methods but the industry, e.g. games, automobile or crisis management, provides expertise from its users (e.g. evaluators and developers). Thus, this firm has a potential to expand its markets through its users.

Technological products have entered the crisis management sector of innovation for operations and for training (e.g. XVR Virtual Training for Safety and Security Professionals from E-Semble www.e-semble.com). Such developments are likely to be expensive and take a long time to perfect in interaction with the other actors and networks in the sector. From the software methodological perspective it is well known that shifts in paradigms have spurred new technological developments. Examples are Integrated Development Environments tailored for modelling (e.g. ArgoUML from Tigris 
(tigris.org)) and project management tools for agile development (e.g. ScrumWorks). Some are opensource developments and others are proprietary software. Different types of networks are formed around these. Communities for individual products target mainly users, but there are examples of networks of firms providing a common platform or quality assurance (e.g. Collabnet [85]). In some of the technologies for interactive systems evaluation the same can be seen, e.g. for websites. A lack of obvious drivers to innovate evaluation methods, i.e. that no firms desire to innovate them into products, may dampen any interest in transferring them between sectors and hence evolving them. This may be the Achilles' heel of evaluation methods.

\section{Conclusions}

In this paper, a sectoral system of innovation approach has been used to analyse the constituents of a selected sector, crisis management training. Two case studies were described where heuristics evaluation and user testing were applied with simulation software that allows training of crisis management. The analysis showed that the transfer of methods to the crisis management sector can be adequately described using the framework. The analysis resulted in a process model, describing the transfer of methodological knowledge within the sectoral system of innovation framework. The process model consists of the components of the framework but emphasizes demand stimulating transfer of knowledge and peripheral knowledge from other areas.

From the two case studies we have learned that the interaction within the sector of crisis management is as important as the interaction with the dimensions of methodological developments of the products used. We have learned that the sectoral system of innovation for any one domain is so multifaceted that it is necessary to look at the interaction between its aspects, and for each aspect its knowledge, technologies, actors, networks and institutions. The methods transfer process explicated in this paper can contribute to the work of different actors. For researchers and method developers, the sectoral system of innovation can serve as a tool to identify the demands of method 
transfer, the landscapes in which methods are transferred, and the transfer operations of

evolutionary theory and innovation. As methodologists, developers and usability evaluators may rely on support from networks and institutions and be assured that inventions are created based on their needs. Crisis managers, as instructors or trainees, are ensured that efficiency in the discipline drives innovation in an iterative and collective process involving several actors. By monitoring the stimulus of the transfer innovation managers can better understand the needs for methods transfer.

\section{Acknowledgement}

The research leading to these results has received funding from COST Action IC0904, Twintide, and the European Union Seventh Framework Programme (FP7/2007-2013) under grant agreement no. [FP7-242474], CRISIS.

\section{References}

1. Baldwin TT, Ford JK (1988) TRANSFER OF TRAINING: A REVIEW AND DIRECTIONS FOR FUTURE RESEARCH. Personnel Psychology 41 (1):63-105. doi:10.1111/j.1744-6570.1988.tb00632.x

2. Bekkers R, Maria BFI (2008) Analysing knowledge transfer channels between universities and industry: To what degree do sectors also matter? Research Policy 37 (10):1837-1853. doi:http://dx.doi.org/10.1016/j.respol.2008.07.007

3. Fernie S, Green SD, Weller SJ, Newcombe R (2003) Knowledge sharing: Context, confusion and controversy. International Journal of Project Management 21 (3):177-187. doi:http://dx.doi.org/10.1016/S0263-7863(02)00092-3

4. Bush WR (2007) Software, regulation, and domain specificity. Information and Software Technology 49 (1):44-54. doi:http://dx.doi.org/10.1016/j.infsof.2006.08.007

5. Shepherd IDH, Bleasdale-Shepherd ID (2011) The design-by-adaptation approach to universal access: Learning from videogame technology. Universal Access in the Information Society 10 (3):319336

6. Sutcliffe A, Gault B (2004) Heuristic evaluation of virtual reality applications. Interacting with Computers $16(4): 831-849$

7. Nielsen J (1994) Enhancing the explanatory power of usability heuristics. Paper presented at the Proceedings of the SIGCHI Conference on Human Factors in Computing Systems, Boston, Massachusetts, USA,

8. Hvannberg ET, Halldórsdóttir G, Rudinsky J Exploitation of heuristics for virtual environments. In: Proceedings of the 7th Nordic Conference on Human-Computer Interaction: Making Sense Through Design, 2012. ACM, pp 308-317

9. Cronholm S, Neubauer M, Stary C Guiding Situated Method Transfer in Design and Evaluation: Exploring Concepts, Activities and Process. Universal Access in the Information Society 10. Woolrych A, Hornbæk K, Frøkjær E, Cockton G (2011) Ingredients and meals rather than recipes: A proposal for research that does not treat usability evaluation methods as indivisible wholes. International Journal of Human-Computer Interaction 27 (10):940-970 
11. Malerba F, Orsenigo L (1990) Technological regimes and patterns of innovation: A theoretical and empirical investigation of the Italian case. Evolving technology and market structure: Studies in Schumpeterian Economics:283-305

12. Malerba F, Orsenigo L (1993) Technological Regimes and Firm Bebavior. Industrial and corporate change $2(1): 45-71$

13. Malerba $F(2005)$ Sectoral systems of innovation: A framework for linking innovation to the knowledge base, structure and dynamics of sectors. Economics of Innovation and New Technology 14 (1-2):63-82. doi:10.1080/1043859042000228688

14. Rosenberg N (1982) Inside the Black Box: Technology and Economic Change. Cambridge University Press, New York,

15. Mowery DC, Nelson RR (1999) Sources of industrial leadership: Studies of seven industries.

Cambridge University Press,

16. Pavitt K (1984) Sectoral patterns of technical change: Towards a taxonomy and a theory.

Research Policy 13 (6):343-373

17. Nelson RR, Sidney G (2005) Winter (1982) An evolutionary theory of economic change.

Cambridge: Belknap

18. Lang KR, Arakji RY Evolution of Innovations Across Web 2.0 Service Platforms through Mutation, Natural Selection and Reuse. In: System Sciences (HICSS), 2010 43rd Hawaii International Conference on, 5-8 Jan. 2010 2010. pp 1-10. doi:10.1109/hicss.2010.193

19. Antunes P, Herskovic V, Ochoa SF, Pino JA (2012) Structuring dimensions for collaborative systems evaluation. ACM Comput Surv 44 (2):1-28. doi:10.1145/2089125.2089128

20. Gulliksen J, Sandblad B (1995) Domain-specific design of user interfaces. International Journal of Human-Computer Interaction 7 (2):135-151

21. Redish J (2007) Expanding usability testing to evaluate complex systems. Journal of usability studies 2 (3):102-111

22. Rudinsky J, Hvannberg ET Consolidating Requirements Analysis Models for a Crisis Management Training Simulator. In: Proceedings of the 8th International ISCRAM Conference-Lisbon, 2011.

23. Van Merriënboer JJ, Kirschner PA, Kester L (2003) Taking the load off a learner's mind: Instructional design for complex learning. Educational Psychologist 38 (1):5-13

24. Merrill MD (2002) First principles of instruction. Educational Technology Research and Development 50 (3):43-59

25. Freitas Sd, Neumann T (2009) The use of 'exploratory learning' for supporting immersive learning in virtual environments. Computers \& Education 52 (2):343-352.

doi:http://dx.doi.org/10.1016/j.compedu.2008.09.010

26. van Berlo MPW, Lowyck J, Schaafstal A (2007) Supporting the instructional design process for team training. Computers in Human Behavior 23 (3):1145-1161.

doi:http://dx.doi.org/10.1016/j.chb.2006.10.007

27. Barnett J, Wong W, Westley D, Adderley R, Smith M Startle reaction: Capturing experiential cues to provide guidelines towards the design of realistic training scenarios. In: Proceedings of the Human Factors and Ergonomics Society Annual Meeting, 2012. SAGE Publications, pp 2477-2481

28. Morin M, Jenvald J, Thorstensson M (2000) Computer-supported visualization of rescue operations. Safety Science 35 (1-3):3-27. doi:http://dx.doi.org/10.1016/S0925-7535(00)00019-9 29. Roberts AR (2005) Crisis intervention handbook: Assessment, treatment, and research. Oxford University Press, USA,

30. Lindemann E (1944) Symptomatology and management of acute grief. Am J Psychiatry 151 (6 Suppl):155-160

31. Gislason SR, Hassenkam T, Nedel S, Bovet N, Eiriksdottir ES, Alfredsson HA, Hem CP, Balogh ZI, Dideriksen K, Oskarsson N, Sigfusson B, Larsen G, Stipp SLS (2011) Characterization of Eyjafjallajökull volcanic ash particles and a protocol for rapid risk assessment. Proceedings of the National Academy of Sciences 108 (18):7307-7312. doi:10.1073/pnas.1015053108 
32. Lund KA, Benediktsson K (2011) Inhabiting a risky earth: The Eyjafjallajökull eruption in 2010 and its impacts (Respond to this article at http://www.therai.org.uk/at/debate). Anthropology Today 27 (1):6-9. doi:10.1111/j.1467-8322.2011.00781.x

33. Rudinsky J, Hvannberg ET (Submitted) Forms of voice communication for crisis management training in a virtual environment.

34. Halldorsdottir G, Hvannberg E (2011) An Analysis of a Plane Crash Training Event After Action Review (trans: Sciences SoEaN). University of Iceland Reykjavik

35. Van Merriënboer JJ, Clark RE, De Croock MB (2002) Blueprints for complex learning: The 4C/IDmodel. Educational Technology Research and Development 50 (2):39-61

36. Rubin J, Chisnell D (2008) Handbook of Usability Testing: Howto Plan, Design, and Conduct Effective Tests. Wiley,

37. Gulliksen J, Boivie I, Göransson B (2006) Usability professionals-current practices and future development. Interacting with Computers 18 (4):568-600

38. Holzinger A (2005) Usability engineering methods for software developers. Commun ACM 48

(1):71-74. doi:10.1145/1039539.1039541

39. Petrie H, Bevan N (2009) The evaluation of accessibility, usability and user experience. The Universal Access Handbook:10-20

40. Chilana PK, Wobbrock JO, Ko AJ Understanding usability practices in complex domains. In: Proceedings of the 28th international conference on Human factors in computing systems, 2010. ACM, pp 2337-2346

41. Nielsen J, Molich R (1990) Heuristic evaluation of user interfaces. Paper presented the Proceedings of the SIGCHI Conference on Human Factors in Computing Systems, Seattle, Washington, USA,

42. Hertzum M, Molich R, Jacobsen NE (2013) What you get is what you see: Revisiting the evaluator effect in usability tests. Behaviour \& Information Technology (ahead-of-print):1-19

43. Nielsen J Finding usability problems through heuristic evaluation. In: Proceedings of the SIGCHI conference on Human factors in computing systems, 1992. ACM, pp 373-380

44. Følstad A, Hornbæk K (2010) Work-domain knowledge in usability evaluation: Experiences with Cooperative Usability Testing. Journal of Systems and Software 83 (11):2019-2030.

doi:http://dx.doi.org/10.1016/j.jss.2010.02.026

45. Muller MJ, Matheson L, Page C, Gallup R (1998) Methods \& tools: participatory heuristic evaluation. interactions $5(5): 13-18$

46. Chattratichart J, Brodie J Extending the heuristic evaluation method through contextualisation. In: Proceedings of the Human Factors and Ergonomics Society Annual Meeting, 2002. SAGE Publications, pp 641-645

47. Hornbæk K, Frokjaer E (2004) Usability inspection by metaphors of human thinking compared to heuristic evaluation. International Journal of Human-Computer Interaction 17 (3):357-374

48. Väänänen-Vainio-Mattila K, Wäljas M (2009) Developing an expert evaluation method for user eXperience of cross-platform web services. Paper presented at the Proceedings of the 13th International MindTrek Conference: Everyday Life in the Ubiquitous Era, Tampere, Finland, 49. Ling C, Salvendy G (2005) Extension of heuristic evaluation method: A review and reappraisal. Ergonomia IJE\&HF 27 (3):179-197

50. Hollingsed T, Novick DG (2007) Usability inspection methods after 15 years of research and practice. Paper presented at the Proceedings of the 25th annual ACM international conference on Design of communication, El Paso, Texas, USA,

51. ISO/IEC (2010) International standard 9241-210: Ergonomics of human-system interaction, Part 210: Human-centered design for interactive systems.

52. ISO/IEC (2006) International standard 9241-110: Ergonomics of human-system interaction, Part 110: Dialogue Principles systems.

53. Lavery D, Cockton G, Atkinson M (1996) Heuristic Evaluation. Usability Evaluation Materials. Tech. Rep. TR-1996-15). Glasgow, Scotland: University of Glasgow. http://www. dcs. gla. ac. 
uk/asp/materials/HE_1. 0/materials. pdf (http://www. dcs. gla. ac. uk/asp/materials/HE_1.

$0 /$ materials. pdf),

54. Baker K, Greenberg S, Gutwin C (2001) Heuristic evaluation of groupware based on the mechanics of collaboration. In: Engineering for human-computer interaction. Springer, pp 123-139

55. Squires D, Preece J (1999) Predicting quality in educational software:: Evaluating for learning, usability and the synergy between them. Interacting with Computers 11 (5):467-483

56. Bevan N (2009) Extending Quality in Use to Provide a Framework for Usability Measurement. In: Kurosu M (ed) Human Centered Design, vol 5619. Lecture Notes in Computer Science. Springer Berlin Heidelberg, pp 13-22. doi:10.1007/978-3-642-02806-9_2

57. Bøegh J (2008) A new standard for quality requirements. IEEE Software 25 (2):57-63

58. Schmettow M, Vos W, Schraagen JM (In press, online) With how many users should you test a medical infusion pump? Sampling strategies for usability tests on high-risk systems. Journal of Biomedical Informatics (0). doi:http://dx.doi.org/10.1016/j.jbi.2013.04.007

59. Law EL-C, Abrahão S, Vermeeren AP, Hvannberg ET Interplay between User Experience Evaluation and System Development: State of the Art. In: International Workshop on the Interplay between User Experience (UX) Evaluation and System Development (I-UxSED 2012), Copenhagen, Denmark, 2012. CEUR Workshop proceedings $p 1$

60. Law ELC (2006) Evaluating the downstream utility of user tests and examining the developer effect: A case study. International Journal of Human-Computer Interaction 21 (2):147-172

61. Kirkpatrick DL, Kirkpatrick JD (2009) Evaluating Training Programs: The Four Levels (Large Print 16pt). Readhowyouwant,

62. Wright PC, Monk AF (1991) The use of think-aloud evaluation methods in design. SIGCHI Bull 23 (1):55-57. doi:10.1145/122672.122685

63. McGrath JE (1984) Groups: Interaction and performance, vol 14. Prentice-Hall Englewood Cliffs, NJ,

64. Reason JT (2008) The human contribution: unsafe acts, accidents and heroic recoveries. Ashgate Publishing,

65. Gutwin C, Greenberg S The mechanics of collaboration: Developing low cost usability evaluation methods for shared workspaces. In: Enabling Technologies: Infrastructure for Collaborative

Enterprises, 2000.(WET ICE 2000). Proeedings. IEEE 9th International Workshops on, 2000. IEEE, pp 98-103

66. Brooke J (1996) SUS: A "quick and dirty" usability scale. In: Jordan PW, Thomas B, McClelland IL, Weerdmeester B (eds) Usability Evaluation in Industry Taylor and Francis, pp 189-194

67. Jeffries R, Miller JR, Wharton C, Uyeda K (1991) User interface evaluation in the real world: a comparison of four techniques. Paper presented at the Proceedings of the SIGCHI Conference on Human Factors in Computing Systems, New Orleans, Louisiana, USA,

68. Olmsted-Hawala EL, Murphy ED, Hawala S, Ashenfelter KT (2010) Think-aloud protocols: a comparison of three think-aloud protocols for use in testing data-dissemination web sites for usability. Paper presented at the Proceedings of the SIGCHI Conference on Human Factors in Computing Systems, Atlanta, Georgia, USA,

69. Kjeldskov J, Skov MB, Stage J Instant data analysis: conducting usability evaluations in a day. In:

Proceedings of the third Nordic conference on Human-computer interaction, 2004. ACM, pp 233-240 70. Bruun A, Stage J Training software development practitioners in usability testing: an assessment acceptance and prioritization. In: Proceedings of the 24th Australian Computer-Human Interaction Conference, 2012. ACM, pp 52-60

71. Norgaard M, Hornbæk K (2006) What do usability evaluators do in practice?: an explorative study of think-aloud testing. Paper presented at the Proceedings of the 6th conference on Designing Interactive systems, University Park, PA, USA,

72. Folstad A, Law EL-C, Hornbæk K (2010) Analysis in usability evaluations: an exploratory study. Paper presented at the Proceedings of the 6th Nordic Conference on Human-Computer Interaction: Extending Boundaries, Reykjavik, Iceland, 
73. Kim JH, Gunn DV, Schuh E, Phillips B, Pagulayan RJ, Wixon D (2008) Tracking real-time user experience (TRUE): a comprehensive instrumentation solution for complex systems. Paper presented at the Proceedings of the SIGCHI Conference on Human Factors in Computing Systems, Florence, Italy, 74. Tuch AN, Trusell R, Hornb K, \#230 (2013) Analyzing users' narratives to understand experience with interactive products. Paper presented at the Proceedings of the SIGCHI Conference on Human Factors in Computing Systems, Paris, France,

75. Grudin J (1991) CSCW. Commun ACM 34 (12):30-34. doi:10.1145/125319.125320

76. Bangor A, Kortum PT, Miller JT (2008) An Empirical Evaluation of the System Usability Scale. International Journal of Human-Computer Interaction 24 (6):574-594.

doi:10.1080/10447310802205776

77. Bangor A, Kortum P, Miller J (2009) Determining what individual SUS scores mean: Adding an adjective rating scale. Journal of usability studies 4 (3):114-123

78. van den Haak M, De Jong M, Jan Schellens P (2003) Retrospective vs. concurrent think-aloud protocols: Testing the usability of an online library catalogue. Behaviour \& Information Technology 22 (5):339-351. doi:10.1080/0044929031000

79. Hays RT, Singer MJ (1989) Simulation fidelity in training system design: bridging the gap between reality and training. Springer-Verlag New York,

80. Hvannberg Impact of Sensory and Collaborative Contexts on Usability Evaluation Methods

Resources. In: CHI 2013 Workshop Made for sharing: HCl Stories of Transfer, Triumph and Tragedy, Paris, April 27th 2013, 2013. pp 23-28

81. Bjorner D (2006) Software Engineering 3: Domains, Requirements, and Software Design vol 3.

Texts in Theoretical Computer Science. An EATCS Series. Springer, Berlin

82. Wenger E (2000) Communities of Practice and Social Learning Systems. Organization 7 (2):225246. doi:10.1177/135050840072002

83. Paulk MC, Curtis B, Chrissis MB, Weber CV (1993) Capability maturity model, version 1.1.

Software, IEEE 10 (4):18-27. doi:10.1109/52.219617

84. Ferreira AL, Machado RJ, Paulk MC Quantitative Analysis of Best Practices Models in the Software Domain. In: Software Engineering Conference (APSEC), 2010 17th Asia Pacific, Nov. 30 2010-Dec. 3 2010 2010. pp 433-442. doi:10.1109/apsec.2010.56

85. Webster M (2005) The requirements for managing the geographically distributed development organization and the collabnet solution. White Paper, IDC 
Table 1 Basic structure of a sectoral system of innovation

\begin{tabular}{|c|c|c|c|c|c|}
\hline \multicolumn{2}{|l|}{ Sectoral system } & \multicolumn{3}{|l|}{ Building blocks } & \\
\hline & & $\begin{array}{l}\text { Knowledge and } \\
\text { Technologies }\end{array}$ & $\begin{array}{l}\text { Actors and } \\
\text { Networks }\end{array}$ & Institutions & \\
\hline \multirow[t]{2}{*}{ Transformation } & Evolutionary theory & Variety creation & Selection & Replication & \\
\hline & Innovation system & Interaction & Iteration & Interdisciplinary & Learning \\
\hline
\end{tabular}


Table 2 Sectoral system of innovation for crisis management

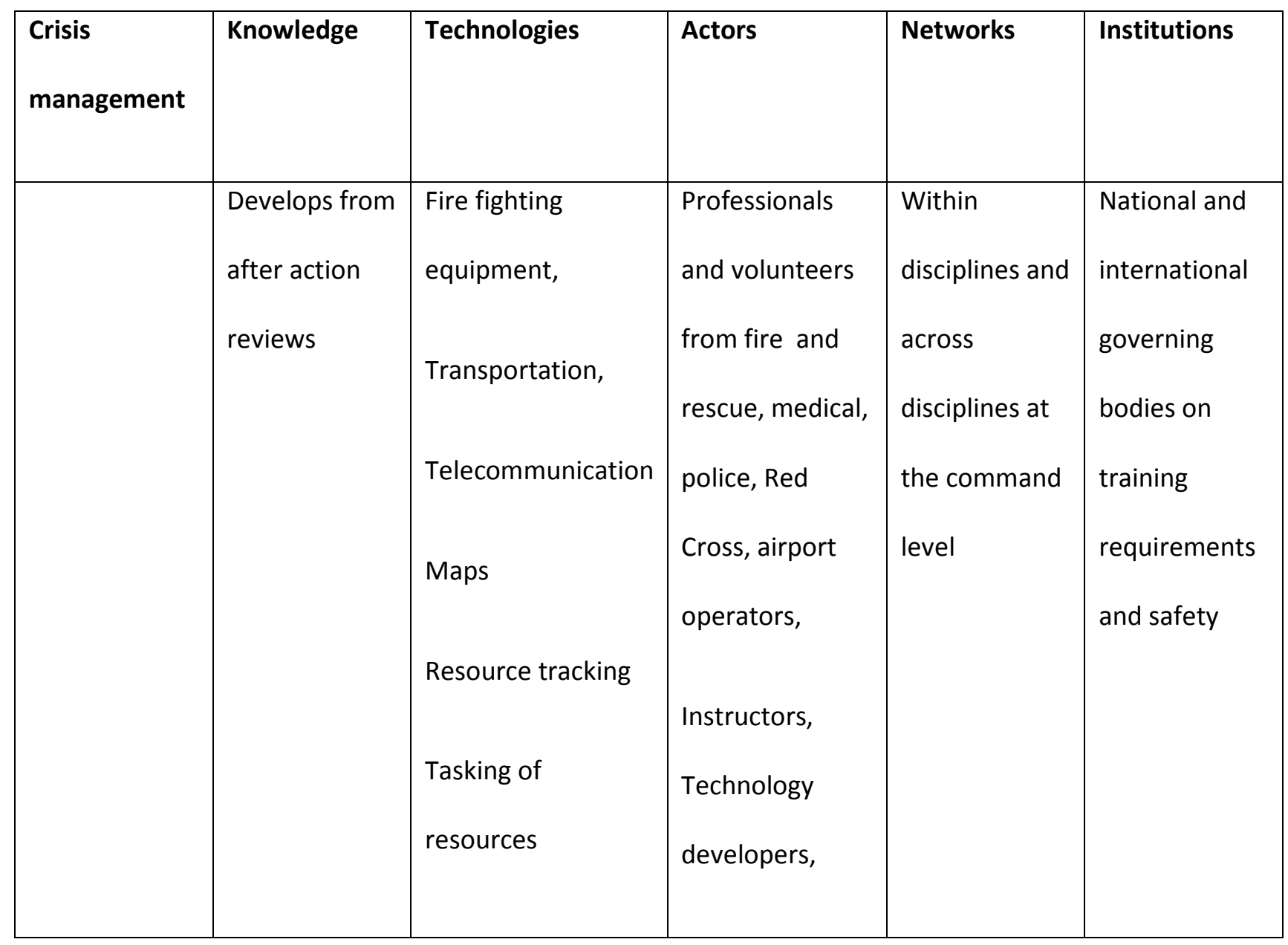




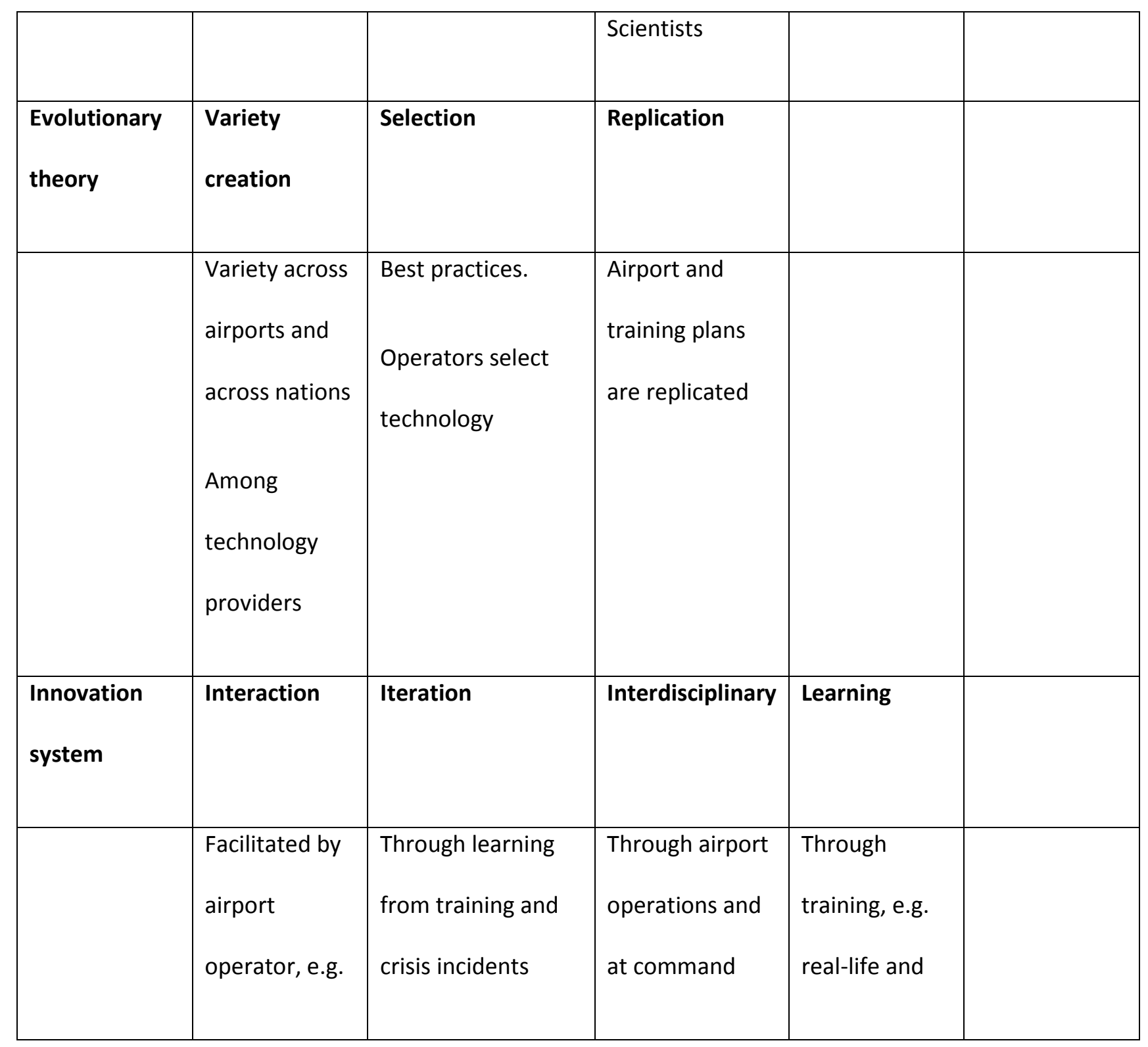




\begin{tabular}{|c|c|c|c|c|}
\hline & $\begin{array}{l}\text { crisis manager } \\
\text { Between } \\
\text { operations } \\
\text { and } \\
\text { technology } \\
\text { provider } \\
\text { through } \\
\text { product } \\
\text { owner }\end{array}$ & $\begin{array}{l}\text { Technology } \\
\text { developer with } \\
\text { new versions }\end{array}$ & $\begin{array}{l}\text { level } \\
\text { Technology } \\
\text { developer } \\
\text { operators and } \\
\text { with other } \\
\text { sectors than CM }\end{array}$ & $\begin{array}{l}\text { table-top } \\
\text { Technology } \\
\text { developer } \\
\text { through } \\
\text { observations } \\
\text { and } \\
\text { evaluations }\end{array}$ \\
\hline
\end{tabular}


Table 3 Evolution of two case studies

\begin{tabular}{|c|c|c|c|c|c|c|}
\hline $\begin{array}{l}\text { Transfer operators } \\
\text { applied in Crisis } \\
\text { Management Training } \\
\text { evaluation case studies }\end{array}$ & Selection & $\begin{array}{l}\text { Variety } \\
\text { creation }\end{array}$ & Composition & Adaptation & $\begin{array}{l}\text { Repli- } \\
\text { cation }\end{array}$ & $\begin{array}{l}\text { Identified gaps } \\
\text { in case studies }\end{array}$ \\
\hline Heuristics evaluation & $\begin{array}{l}\text { Heuristics list of } \\
\text { Sutcliffe and Gault was } \\
\text { selected from a variety } \\
\text { of lists. }\end{array}$ & & & $\begin{array}{l}\text { Conformance } \\
\text { questions added } \\
\text { for each } \\
\text { heuristics to } \\
\text { increase } \\
\text { efficiency. }\end{array}$ & & $\begin{array}{l}\text { Perspectives of } \\
\text { communication and } \\
\text { sound missing. } \\
\text { Collaboration included } \\
\text { partly. }\end{array}$ \\
\hline User testing & $\begin{array}{l}\text { Using the Collaborative } \\
\text { Systems Framework to } \\
\text { select a method based }\end{array}$ & $\begin{array}{l}\text { Qualitative } \\
\text { analysis of }\end{array}$ & $\begin{array}{l}\text { User testing, } \\
\text { Systematic Usability } \\
\text { Survey and post-test }\end{array}$ & $\begin{array}{l}\text { Post-task } \\
\text { questions } \\
\text { changed to post- }\end{array}$ & & $\begin{array}{l}\text { Lack of instruments for } \\
\text { assessing sound } \\
\text { perception and verbal }\end{array}$ \\
\hline
\end{tabular}




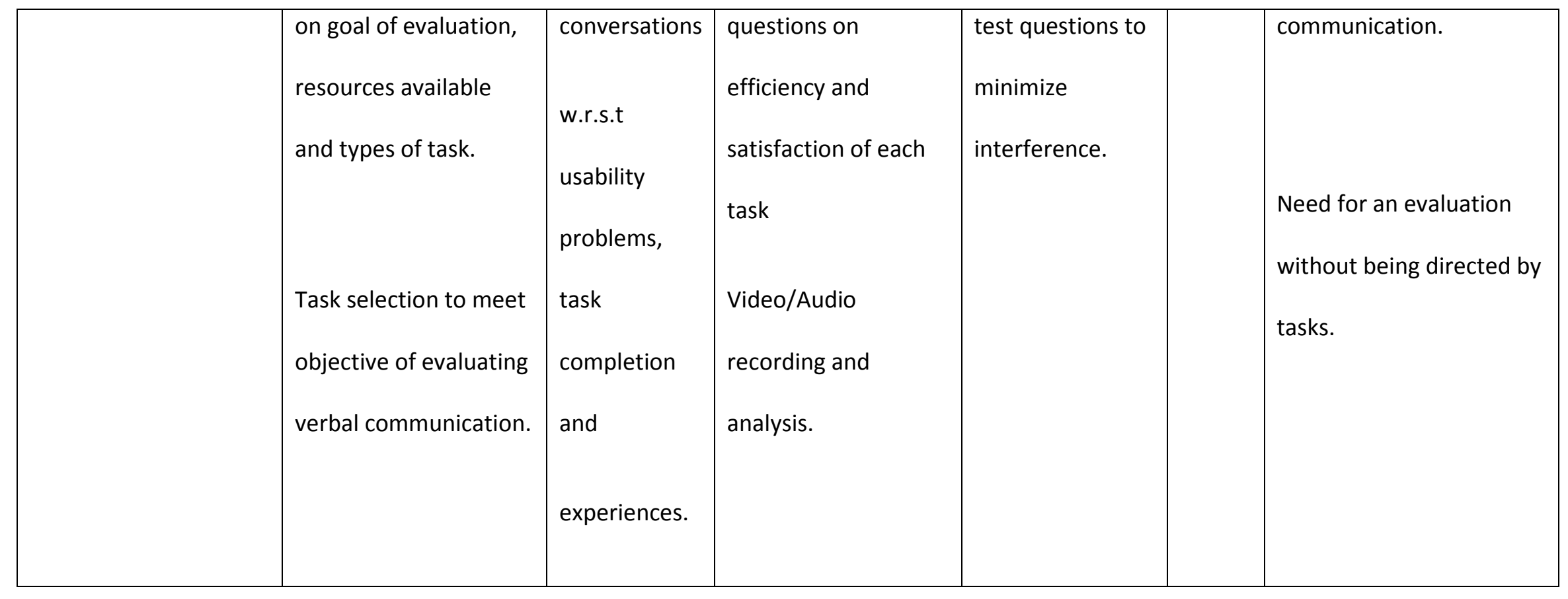


S1: Sectoral system of

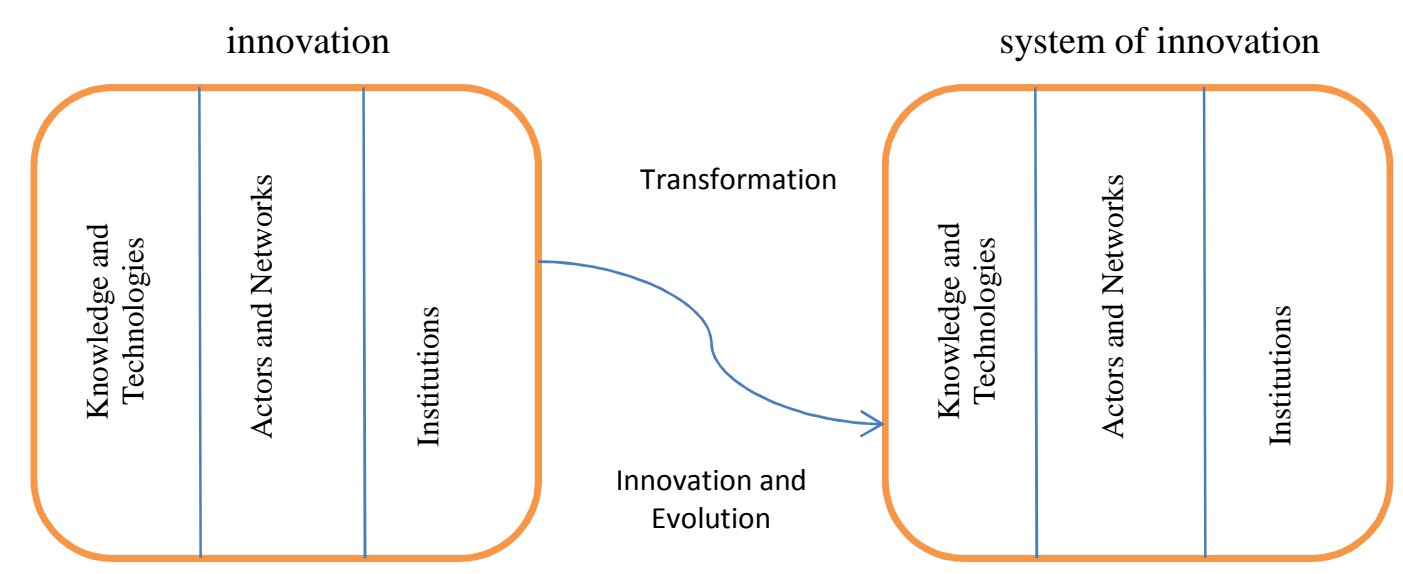

Figure 1 Transformation of a sectoral system 


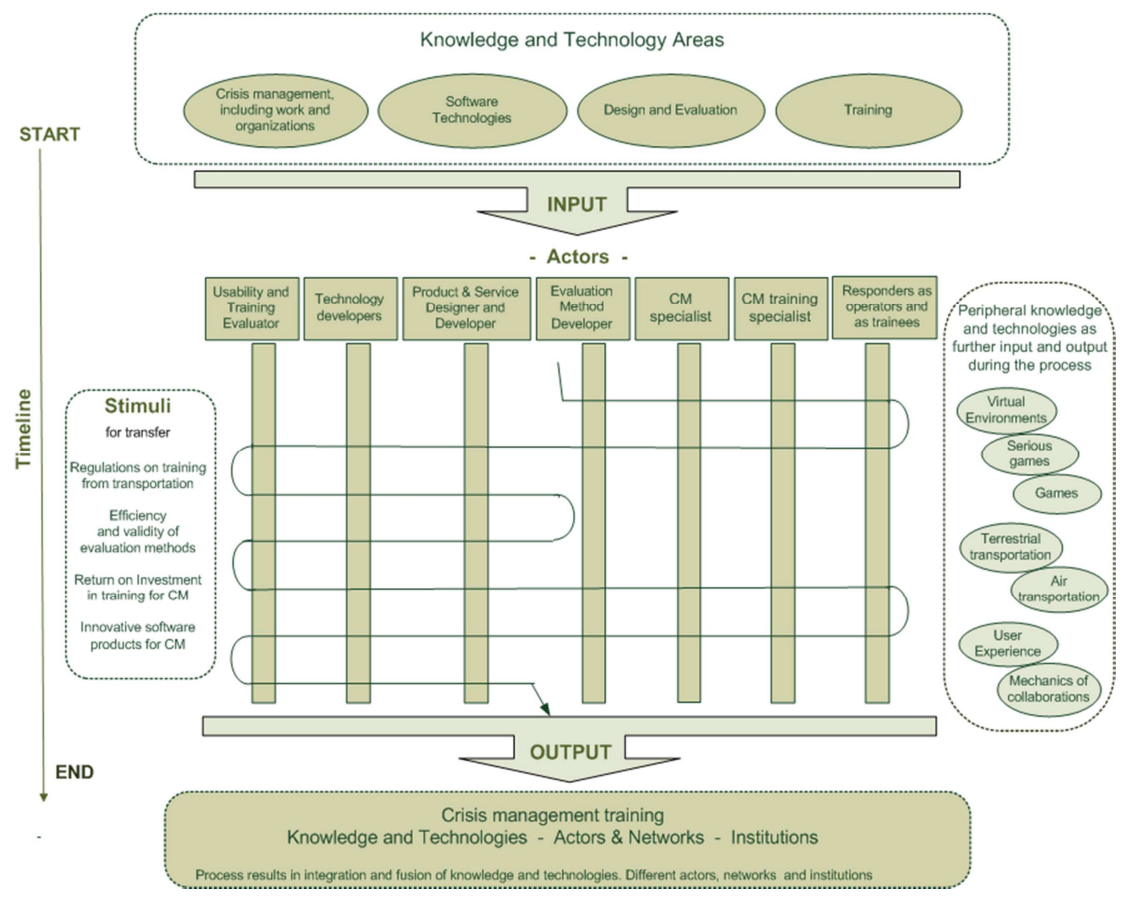

Figure 2 Process of transformation for evaluation methods 